\title{
Reallocation of Shafa Hospital Beds in Kerman Using Goal Programming Model
}

\author{
Mohammad Hossein Mehrolhasani ${ }^{1}$, Sajad Khosravi², Mahya Tohidi ${ }^{3}$
}

${ }^{1}$ Ph.D. of Health Services Management, Associate Professor, Modeling in Health Research Center, Institute for Futures Studies in Health, Kerman University of Medical Sciences, Kerman, Iran

${ }^{2} \mathrm{Ph} . \mathrm{D}$. Candidate of Health Services Management, Health Services Management Research Center, Institute for Futures Studies in Health, Kerman University of Medical Sciences, Kerman, Iran

${ }^{3}$ M.Sc. of Executive Management, Medical Informatics Research Center, Institute for Futures Studies in Health, Kerman University of Medical Sciences, Kerman, Iran

\section{Type of article: Original}

\begin{abstract}
Introduction: In order to improve health, hospital sources such as beds and staffing should be properly allocated and used. The aim of this study is reallocation of Shafa hospital beds in Kerman using a goal-programming model.

Methods: This study was an applied cross-sectional study, which used the goal programming model and software WinQSB to optimize bed allocation. By review of the literature and interviews with experts, the constraints in beds allocation were identified, and using the collected data the desired model was designed.

Results: Hospital beds were redistributed based on the constraints of the goal-programming model and objectives. The results showed that there was a shortage of beds in departments such as burns, GICU, HICU, cardiac surgery, emergency, and orthopedics, and excess of beds in the ear, nose, and throat (ENT), ophthalmology, and neurology departments.

Conclusion: It is anticipated that the optimal allocation of hospital beds, regarding hospital activity indicators, can lead to greater justice in the provision of services and a better distribution of resources.

Keywords: Goal programming, Inpatient bed, Bed allocation
\end{abstract}

\section{Introduction}

Today, the optimal allocation of resources in all sectors of production, services, industry etc., is very important because optimal use of resources can be very effective in efficiency and effectiveness (1). Organizations are faced with multiple targets for budgeting and resource allocation. Therefore, planning for optimal use of existing resources and providing the desired aims are inevitable. The health sector is one of the most important and effective sectors in each country whose performance has a significant impact on other sectors. Thus, in most countries the allocation of resources in this sector is important for governments (2). Because paying attention to health care and investments in this area, increase labor productivity and production; therefore, adequate resource allocation and optimal utilization of resources in this sector is greatly important (3). With the increasing cost of health care, policy makers of health sectors focus on the most expensive services sector, which is hospital services. Almost half of the total costs of the health sector were allocated to hospital services. Therefore, it is necessary to improve efficiency of these services by reducing costs and using the potential capacities of health care institutions $(4,5)$. Health system decision-makers, especially in the hospital setting are faced with limited resources and the unlimited needs of people; this makes special status of economics in hospitals. These centers must meet the growing trend of patients' needs to receive optimal services on one hand and are always faced with limited resources and funding on the other hand (6). One of the main problems within the hospital environment is beds dedicated to patients. Shortage and inappropriate distribution of beds results in reduce of services to patients and poor distribution of nurses, doctors, and medical

\section{Corresponding author:}

Sajad Khosravi, Department of Health Services Management, School of Management and Medical Informatics, Kerman University of Medical Sciences, Kerman, Iran. Tel: +98.3433529985, Email: Khosravi.sajad@yahoo.com Received: September 12, 2015, Accepted: February 12, 2016, Published: August 2016 iThenticate screening: February 12, 2016, English editing: July 20, 2016, Quality control: August 04, 2016 (C) 2016 The Authors. This is an open access article under the terms of the Creative Commons Attribution-NonCommercialNoDerivs License, which permits use and distribution in any medium, provided the original work is properly cited, the use is non-commercial and no modifications or adaptations are made. 
equipment (7). In order to improve health, hospital sources such as beds, staffing, etc., should be distributed by using an appropriate plan. Given the importance of hospital resources and efficient allocation of personnel and hospital equipment based on the number of beds in each section, distribution of beds is one of the most important issues of hospital management today (8). The efficient allocation of hospital beds for each sector is an important issue for health management. Hospital managers make great efforts to optimize the number of hospital beds to promote their services to patients. As it is, clear allocation of beds for each hospital and redistribution of them in different periods is an essential issue (9).

In formulation and allocation of resources, modeling is a regular tool that can provide necessary information for decisions to achieve your goals. Planners using models can examine systematically some relationships between the factors. They understand the relationships that may not be possible simply without using the modals. From a model, we expect to meet our needs of planning. Some of these requirements include predictability, flexibility, ability of performance evaluation, optimal allocation of resources, and simplicity of use (10). Among existing models, stochastic simulation and goal programming are the ways for the allocation of hospital resources, particularly hospital beds (11). Goal programming is a multi-criteria decision-making model in the field of linear algebra (12). The main role of goal programming is considering the limitations and goals and decision variables as well as removing poor human reasoning in planning and decision-making. This role will have special effects when looking to optimize several factors simultaneously (13). Numerous studies in the world have used practical research techniques in resource allocation in the health sector $(8,9)$. In Iran, these techniques have been used a lot in the health sector. Abedi, in his study, used goal programming to allocate resources in the educational sector of the Ministry of Health (14). Noori Hekmat in his study used this technique to determine the optimal number of required nurses in the emergency department (15), Nasrolahi also used this technique to model scheduling of work shifts of nurses in different shifts in hospital (16), and Ataollahi, in order to allocate hospital beds (17). According to studies, the importance of optimum allocation of resources in Iran has been identified in these studies. Since Shafa hospital in Kerman is among the first hospitals of this city, and given that the new building of the hospital is under construction, optimum allocation of resources, particularly bed allocation to the sectors of the hospital, reflects the importance of this issue. Therefore, this research is to redistribute inpatient beds of Shafa hospital in Kerman University of Medical Sciences using a goal-programming model.

\section{Material and Methods}

This study was a cross-sectional and applied study. So that after the implementation of models by software, in order to be utilized the result of this modeling was delivered to the research and development department of Shafa Hospital. Shafa therapeutic training center in Kerman is a university hospital. Construction began in 1960 and was in full operation by 1964. This therapeutic training center has 503 approved beds and infrastructure of 34,000 square meters in an area of 91,000 square meters and some of its wards were located on two floors. This study was carried out, using a goal programming model to solve the problems by using software WinQSB in order to calculate the optimum number of beds in each hospital ward to prevent non-optimum beds, and ultimately provide an appropriate model resulting in increased efficiency and productivity of hospital. In this study, by referring to section of quality management in Shafa Hospital, and examining related documents, required data were gathered The data includes estimating the total number of active hospital beds for each ward, based on existing hospital statistics, the total number of hospital nurses, nursing-available work hours for each hospital ward, the average care for each patient of each ward, along with the monthly average of bed occupancy rate, and the average waiting time for bed use by using the HIS system and patient's information system in the hospital reception, from the time of his request for service, to the time of providing it . By literature review and interviews with experts, the important limitations in allocation of beds were identified and then the goals were written based on these limitations, and objective priorities were identified through literature review and interviews with experts, and finally a redistribution program of hospital inpatient beds was written in the WinQSB software environment.

\section{Results}

In this study, 18 wards of Shafa Hospital in Kerman with 401 beds were examined for optimum allocation of hospital beds. The number of nurses working in these wards is 495 people and their working hours per month were calculated as 84834 hours totally. Also in this study to evaluate the limitations and goals, the amount of nursing hours belonging to any beds and the average waiting time for patients in each ward is calculated. In operational planning techniques in order to achieve the objectives of the study, first the constraints and goals are identified. In this study given the importance of each of these goals by literature review and interviews with experts in this field, the intended limitations and goals to allocate beds were identified and prioritized. Table 1 shows one of the most 
important of these limitations and goals. After determining the constraints and goals of the study and entering this information into the WinQSB software, solving the model by this software lead to optimum allocation of beds to each of the studied departments. Table 2 shows the initial number of beds in each department and the optimum number obtained in this study. In addition, in this software for each of the variables, a range of changes can also be defined in order to calculate an optimum number for each variable according to the available hypothesis. In this study according to the available occupancy rate of each department, a range of changes is also considered for the number of beds of each one, which is shown in Table 2.

Table 1. Constraints and Goals of model

\begin{tabular}{|l|l|l|}
\hline \multicolumn{2}{|l|}{$\begin{array}{l}\text { System } \\
\text { constraint }\end{array}$} & None of the departments should be without a bed. The definitive bed allocation should be made \\
\hline Goals & P1 & All active hospital beds should be allocated to departments \\
\cline { 2 - 3 } & P2 & Maximum use of nurse staffing \\
\cline { 2 - 3 } & P3 & Reduced waiting in departments \\
\cline { 2 - 3 } & P4 & $\begin{array}{l}\text { Bed distribution should be proportional to the maximum and minimum number of hours' } \\
\text { nurses work }\end{array}$ \\
\hline
\end{tabular}

Table 2. The number of beds before and after model solving

\begin{tabular}{|l|l|l|l|l|}
\hline \multirow{2}{*}{ Department } & \multicolumn{2}{l|}{ Number of beds before and after model solving } & \multicolumn{2}{l|}{ Variation range } \\
\cline { 2 - 5 } & Before & After & Lower & Upper \\
\hline CCU1 & 12 & 12 & 10 & 18 \\
\hline CCU2 & 12 & 12 & 10 & 18 \\
\hline Neurology & 35 & 30 & 30 & 40 \\
\hline Internal heart & 24 & 20 & 20 & 26 \\
\hline Post angiography & 18 & 18 & 16 & 20 \\
\hline Surgery & 20 & 16 & 15 & 25 \\
\hline ENT & 32 & 25 & 22 & 35 \\
\hline Eye & 48 & 35 & 35 & 52 \\
\hline Burn & 48 & 50 & 40 & 55 \\
\hline GICU & 10 & 15 & 8 & 18 \\
\hline HICU & 13 & 15 & 10 & 20 \\
\hline heart surgery & 20 & 25 & 18 & 28 \\
\hline General operating room & 8 & 10 & 6 & 15 \\
\hline Eye surgery room & 4 & 8 & 4 & 15 \\
\hline heart operating room & 3 & 5 & 3 & 8 \\
\hline Emergency & 40 & 50 & 35 & 55 \\
\hline Rheumatology & 30 & 25 & 25 & 35 \\
\hline Orthopedics & 24 & 30 & 20 & 35 \\
\hline
\end{tabular}

\section{Discussion}

The results of this research in discussing the studied limitations and goals to draw the objective function, show in this research a system constraint, and four goals were selected and examined. After identifying the goals, they were formulated using operational research techniques and finally the objective function was formed. The most important objectives of this study include the maximum use of active beds and manpower, reducing waiting times, and bed distribution according to working hours of nurses. In various studies of allocating hospital beds, these goals are used $(2,17)$. Based on the results obtained from the model and comparing the optimal values with the actual values, the use of goal programming has led to optimizing the allocation of beds. In a study by Ling Gao et al. in the field of modeling done on the allocation of beds, efficiency of goal programming in optimizing the allocation of resources is emphasized (18). The optimum allocation of hospital beds will have a great impact on health management. To redistribute beds, many factors such as bed occupancy rates, patient waiting time, and the number of personnel are involved, so that all the factors affecting the distribution of the beds should be considered together. Results of various studies show that patient's waiting time for a service is one of the factors influencing patient satisfaction, and an important factor in distribution of hospital beds (19), which is taken into consideration in this research and also is employed as one of the efficient variables in allocation of beds. In Kuwait, Ahmed et al. conducted optimum simulation for emergency department services. In this simulation, an appropriate mix of resources was used. The 
results showed a 28 percent increase in efficiency of staff and 40 percent reduction in waiting time (20). The results showed that there was a shortage of beds in departments such as burns, GICU, HICU, cardiac surgery, emergency, orthopedics and excess of beds in the ENT, ophthalmology, and neurology departments. The main reasons for these differences can be occupancy rate of each department, the number of nurses, nursing hours of each department and waiting time and as the main variables, they have been examined in this study. For example, departments that have a higher occupancy rate or high waiting time to receive services have been experiencing shortage of beds in redistribution of the beds so more beds should be allocated to these departments. Conversely, the departments with less waiting time, lower occupancy rate and less nursing hours, were required to have less bed allocation or remained unchanged in redistribution. Bahrami also, in his study using the software GAMS, offered a goalprogramming model for allocating beds in Shahid Mohammadi hospital in Bandar Abbas. The findings of this study indicated that there was an excess of beds in the internal emergency departments, emergency surgery, and general surgery - and shortage of beds in the CCU, ICUOH, and ICUN (21). Rajabi, in a study, tried using a goalprogramming model to offer a criterion for optimum allocation of resources in the Ministry of Health to provinces. The results of this study showed that the proposed method in optimum allocation of funds to the provinces, in the long run, would lead to equity and stability in the provinces (22).

\section{Conclusions}

In the present study, findings showed that the allocation of beds in the hospital is not appropriate to the circumstances of departments, and there is a need to redistribute beds. The importance of this issue is that, with optimum distribution of beds in departments, many problems can be prevented. It is expected that the redistribution of hospital beds, according to hospital activity indicators, can lead to greater equity in delivery of services and better distribution of resources. Therefore, it is suggested that managers use scientific and approved methods of operational research methods in order to optimize the allocation of beds. Further research in this area, and using other methods of operational research in the field of bed allocation, or using the goal programming model, the method of present research in resource allocation in the health system, can be the right direction for studying more in this field.

\section{Acknowledgments:}

The authors thank and appreciate all participants and those who helped in conducting the research, especially the hospital staff of Shafa Hospital in Kerman.

\section{Conflict of Interest:}

There is no conflict of interest to be declared.

Authors' contributions:

All authors contributed to this project and article equally. All authors read and approved the final manuscript.

\section{References:}

1) Tamiz M, Jones D, Romero C. Goal programming for decision making: An overview of the current stateof-the-art. EJOR. 1988; 111(3): 569-81. doi: 10.1016/S0377-2217(97)00317-2.

2) Tingley K, Liebman J. A Goal Programming Example in Public Health Resource Allocation. Management Science. 1984; 30(3): 251-63. doi: 10.1287/mnsc.30.3.279.

3) Arab M, Zarei A, Rahimi A, Rezaiean F, Akbari F. Analysis of Factors Affecting Length of stay in Public Hospitals in Lorestan Province, Iran. Hakim Research Journal. 2010; 12(4): 27-32. Persian

4) Panis LJ, Gooskens M, Verheggen FW, Pop P, Prins MH. Predictors of inappropriate hospital stay: a clinical case study. Int J Qual Health Care. 2003; 15(1): 57-67. doi: 10.1093/intqhe/15.1.57, PMID: 12630801.

5) McDonagh M, Smith $D$, Goddard M. Measuring appropriate use of acute beds: A systematic review of methods and results. Health Policy. 2000; 53(3): 157-84. doi:10.1016/S0168-8510(00)00092-0, PMID: 738896, PMCID: PMC1072080.

6) Karimi I. Health economy. Tehran: Gap Publishing; 2004.

7) Ward DM. Bed Management Collaborative. Queensland Health Quality and Safety Improvement Program, Queensland; 2004.

8) Kokangul A. A combination of deterministic and stochastic approaches to optimize bed capacity in a hospital unit. Comput methods programs biomed. 2008; 90(1): 56-65. doi: 10.1016/j.cmpb.2008.01.001, PMID: 18280609. 
9) McClain JO. A model for regional obstetric bed planning. Health Serv Res. 1978; 13(4): 378. PMCID: PMC1072080.

10) Hopkins GP, Iarreche J, Massy WF. Constrained Optimization Vol. 24. Of A University Administrator's performance Funnctionmgmt. Sci. alloctiong operating Budgets of Academic Units. Socio Econ.Plann. 1977; 21(5): 24.

11) Huarng F. A primary shift rotation nurse scheduling using 0-1 goal programming. Comput Nurs. 1999; 17(3); 135-44. PMID: 10341479.

12) Najjarzadeh A, Rahimi H. The Model of Optimum Allocation of Financial Resources of the Educational Department in Gilan Province to Other Cities Using Goal Programming Method. The Economic Research Quarterly. 2005; 16(4): 12-23. Persian.

13) Rajabi A. The Integration of Goal Programming Method, Fuzzy Logic, and Analytic Hierarchy Process for Optimum Allocation of Financial Resources and Budgeting of Health Ministry to the Provinces of the Country. Ministry of Health and Medical Education. 2006. Persian

14) Abedi Gh, Tayebi J, Delgoshaee B. Goal programming model in resource allocation at education section of the Ministry of Health and Medical Education. Journal of Mazanderan university of medical sciences. 2008; 17(57): 82-7. Persian.

15) NooriHekmat S, Dehnavieh R, Mohammadi N, Poorhosseini S, Rezai F, Mehralhasani MH, et al. Determining the Optimum Number of Nursing Staff Is Needed in Kerman Shafa Hospital Emergency Department. Toloe Behdasht. 2012; 13(2): 140-55. Persian

16) Nasrollahi M. Modeling the Nurse Scheduling in Different Shifts of Babolsar Shafa Hospital. Health Inf Manage. 2015; 11(7): 994. Persian.

17) Atoallahi F, Bahrami MA, Abesi M, Mobasheri F, Khani SH. A Goal Programming Model for Reallocation of Hospitals' Inpatient Beds in Shahid Mohamadi hospital of Bandar abbas. Health care Management Journal. 2014; 5(1): 59-68. Persian.

18) Ling Gao, Liang Lin, Lianlong Gao. Uncertain Models for Bed Allocation. Global Journal of Health Science. 2010; 2(2): 232-7. doi: 10.5539/gjhs.v2n2p232.

19) Choyce M, Maitra A. Satisfaction with the accident and emergency department--a postal survey of general practitioners' views. J Accid Emerg Med. 1996; 13(4): 280-2. doi: 10.1136/emj.13.4.280, PMID: 8832351, PMCID: PMC1342732.

20) Ahmed MA, Alkhamis TM. Simulation optimization for an emergency department healthcare unit in Kuwait. EJOR. 2009; 198(3): 936-42. doi: 10.1016/j.ejor.2008.10.025.

21) Bahrami MA, Ataollahi F, Abesi M, Mobasheri F. A Goal Programming Model for Reallocation of Hospitals' Inpatient Beds. Middle-East Journal of Scientific Research. 2013; 18(11): 1537-43.

22) Rajabi A. Goal Programming: An Effective Approach for Budgeting and Optimal Financial Resource Allocation (Case Study: Budget Allocation in Ministry of Health and Medical Education). Quarterly Journal of Health Accounting. 2013; 1(2): 1-16. Persian. 